\title{
Establishing institutional arrangements on loss and damage under the UNFCCC: the Warsaw International Mechanism for Loss and Damage
}

\author{
Doreen Stabinsky* \\ College of the Atlantic, \\ 105 Eden Street, \\ Bar Harbor, ME 04660, USA \\ Email: doreenstabinsky@gmail.com \\ *Corresponding author
}

\author{
Juan P. Hoffmaister \\ Climate Change Programme, \\ Universidad de la Cordillera, \\ Calle Man Cesped \#500 (prolongacion), \\ Zona La Florida, La Paz, Bolivia \\ Email: juan.hoffmaister@me.com
}

\begin{abstract}
Both the Intergovernmental Panel on Climate Change and non-governmental organisations have begun to point out that there are significant and serious limits to adaptive capacity and possible adaptation to climate change, particularly to slow-onset impacts such as sea level rise, glacial retreat, desertification, and ocean acidification. The legal obligation to act established under the UN Framework Convention on Climate Change and this growing recognition of adaptation limits has elevated the issue of loss and damage in ongoing negotiations. In this paper, we review the evolution, foundations, and rationale for the establishment of the Warsaw International Mechanism for Loss and Damage (WIM) under the Convention, in particular, the role of the Convention in systematically addressing loss and damage in developing countries that are particularly vulnerable to the adverse effects of climate change. We also contribute some forward thinking on how to address needs of developing countries in the context of the operationalisation of the mechanism.
\end{abstract}

Keywords: United Nations Framework Convention on Climate Change; UNFCCC; loss and damage; adaptation; state responsibility; slow onset; institutional arrangements; international mechanism; climate change.

Reference to this paper should be made as follows: Stabinsky, D. and Hoffmaister, J.P. (2015) 'Establishing institutional arrangements on loss and damage under the UNFCCC: the Warsaw International Mechanism for Loss and Damage', Int. J. Global Warming, Vol. 8, No. 2, pp.295-318.

Biographical notes: Doreen Stabinsky is a Professor of Global Environmental Politics at College of the Atlantic in Bar Harbor, Maine. Her current research, policy analysis, and popular writing focuses on the science-policy nexus of climate change, agriculture, and food security, principally in the context of international climate negotiations and the UNFCCC climate regime. She also serves as a consultant and advisor to a number of governments and 
international NGOs on issues of loss and damage, agriculture, and climate change within the UNFCCC regime. She holds a $\mathrm{PhD}$ in Genetics from the University of California, Davis.

Juan P. Hoffmaister is a specialist on international governance and law, with expertise in adaptation, disaster risk reduction, and development. He works for the Universidad de la Cordillera, La Paz, and as a Senior Advisor to the Bolivian Ministry of Foreign Affairs. He is also an associate for the Third World Network and the Stockholm Environment Institute. He also serves as a negotiator for the Group of 77, China in multiple issues related to adaptation. $\mathrm{He}$ is a member of the UNFCCC Adaptation Committee, representing Latin America and the Caribbean. He holds a Master's in Governance and Ecosystems from the University of Stockholm and a Bachelor in Human Ecology and Environmental Policy from the College of the Atlantic.

\section{Introduction}

As reaffirmed once again by the fifth assessment report of the Intergovernmental Panel on Climate Change (IPCC, 2014), extreme climatic events linked to climate change remind us daily that a new climate era is upon us. 'Is climate change happening?' is no longer a meaningful question among the international community. Parties to the United Nations Framework Convention on Climate Change (UNFCCC), at COP16 in Cancún in 2010, recognised that "warming of the climate system is unequivocal". ${ }^{1}$ Meteorologists from the USA to Australia now assert that weather extremes are the new normal. ${ }^{2}$ Yet while there is current political emphasis on the need for mitigation to prevent further climate impacts, the emphasis has not led to meaningful, sufficient, concerted collective action. Indeed, adaptation is now a much more common word in climate negotiations than even a few years ago, and concern is (slowly but steadily) increasing about the severity of impacts that will be felt by the most vulnerable in even a $2{ }^{\circ} \mathrm{C}$ warmer world.

Moreover, both the IPCC (2014) in its recent assessment report and a number of non-governmental organisations (see for example, ActionAid et al., 2012a, 2012b) have begun to draw attention to the fact that there are significant and serious limits to adaptation and adaptive capacity, particularly to slow-onset impacts (see also Dow et al., 2013). As temperatures and sea levels rise, territory will become uninhabitable and unproductive. Soil moisture levels will decrease to the point that cultivation of crops is no longer viable in entire regions. Groundwater sources in coastal areas will become too saline to provide drinking water for people living there. Adaptation will become impossible on low-lying islands and in the most arid regions, leading to permanent loss of lands, livelihoods, and cultural resources (Anderson and Bows, 2011; Hossain, 2010; Kates et al., 2012; New et al., 2011).

The objective of the UN Framework Convention on Climate Change (UNFCCC) provides the overall frame for considerations of loss and damage: 


\begin{abstract}
"The ultimate objective of this Convention and any related legal instruments that the Conference of the Parties may adopt is to achieve, in accordance with the relevant provisions of the Convention, stabilization of greenhouse gas concentrations in the atmosphere at a level that would prevent dangerous anthropogenic interference with the climate system. Such a level should be achieved within a time frame sufficient to allow ecosystems to adapt naturally to climate change, to ensure that food production is not threatened and to enable economic development to proceed in a sustainable manner." (UNFCCC, Article 2)
\end{abstract}

It is this context of legal obligation, coupled with a growing recognition that there are very real limits to adaptation, which garnered the issue of loss and damage a central place in negotiations under the UNFCCC.

At its 18th meeting in Doha, the Conference of the Parties to the UNFCCC decided to establish at COP19 in November 2013, institutional arrangements, such as an international mechanism, to address loss and damage associated with the impacts of climate change in developing countries that are particularly vulnerable to the adverse effects of climate change. ${ }^{3}$ In Warsaw, at COP19, the Parties to the UNFCCC did exactly that, in the creation of the Warsaw International Mechanism for Loss and Damage (WIMLD). ${ }^{4}$

In this brief contribution we briefly review the history of and rationale for the mechanism, and describe necessary functions, anchoring our considerations to the requirements of the Convention's ultimate objective, central elements of the Doha decision, and the reflections presented by Parties during the two-year process leading to the establishment of the mechanism. We begin with an introduction to the conceptual scope of the term 'loss and damage'. Next, we review the legal rationale for addressing loss and damage under the UNFCCC, and then trace the evolution of Parties' understanding of means to assess and address loss and damage. Finally, we analyse the role of the Convention in systematically addressing loss and damage associated with the impacts of climate change in developing countries that are particularly vulnerable to the adverse effects of climate change.

It is our intent in this article to provide an informed perspective on loss and damage under the UNFCCC from inside the negotiations, as both observers of and active participants in the creation of the Warsaw International Mechanism for Loss and Damage.

\title{
2 Defining the scope of loss and damage
}

The phrase 'loss and damage' refers broadly to the entire range of damage and permanent loss "associated with climate change impacts in developing countries that are particularly vulnerable to the adverse effects of climate change" that can no longer be avoided through mitigation nor can be avoided through adaptation ${ }^{5}$ (UNFCCC, 2012). This phrase first appears in UNFCCC texts in the Bali Action Plan (UNFCCC Decision 1/CP.13):

"Decides to launch a comprehensive process to enable the full, effective and sustained implementation of the Convention through long-term cooperative action, now, up to and beyond 2012, in order to reach an agreed outcome and adopt a decision at its fifteenth session, by addressing, inter alia: 
(c) Enhanced action on adaptation, including, inter alia, consideration of:

(iii) Disaster reduction strategies and means to address loss and damage associated with climate change impacts in developing countries that are particularly vulnerable to the adverse effects of climate change;"

Under the UNFCCC Subsidiary Body for Implementation (SBI) work program on loss and damage, established in UNFCCC decision 1/CP.16 (and explained in more detail in Section 3), Parties further elaborated on the meaning, content, and scope of 'loss and damage'.

Damage "might be thought of as impacts that can be repaired or restored (such as windstorm damage to the roof of a building, or damage to a coastal mangrove forest from coastal surges which affect villages)". ${ }^{6}$ Loss "might be thought of as those negative impacts that cannot be repaired or restored (such as loss of geological freshwater sources related to glacial melt or desertification, or loss of culture or heritage associated with potential population redistribution away from areas that become less habitable over time with climate change)". 7

Slow-onset events (or more appropriately impacts, hazards, or disasters) emerged as a central concern under the work program on loss and damage, requiring analysis and actions distinct from and in addition to those addressing extreme events, such as typhoons or cyclones. Slow-onset events were first defined in a footnote to UNFCCC decision 1/CP.16 as "including sea level rise, increasing temperatures, ocean acidification, glacial retreat and related impacts, salinization, land and forest degradation, loss of biodiversity and desertification". While the work program contributed some clarity on the types of impacts that are considered 'slow-onset events', Parties recognised that much remains to be understood regarding how to assess, prevent, and address the loss and damage that will result from such slow-onset hazards.

Further, included in the scope of the work to address loss and damage is further understanding of and means to assess and address non-economic losses and the impacts of climate change on migration, displacement, and human mobility. Parties have achieved some clarity on the kinds of non-economic loss and damage associated with climate impacts - for example loss of burial grounds, culture, ecosystems, territory, livelihoods but much work remains on assessment and means for the redress of non-economic losses. Moreover, many non-economic losses are magnified when they come about through forced relocation and migration due to climate impacts. As such, understanding the impacts of climate change on migration, displacement, and human mobility are integral to assessing and addressing loss and damage.

A final consideration in defining the scope of loss and damage is that damage and permanent loss from climate change derive both from direct harm (i.e., the direct costs of actual unavoidable harms) and forgone development (i.e., the costs of lost and diminished opportunities in developing countries, caused by having to forego development options) from extreme events and slow-onset events. Diminished opportunities or forgone sustainable development necessarily impede progress towards poverty eradication. [See for example Rogers (2012) and Mitchell et al. (2012) on potential climate impacts on sustainable development.] 


\section{Foundations for addressing loss and damage under the UNFCCC}

There are both legal and moral obligations to act to address loss and damage under the UNFCCC, and which are clearly foundational to the decision to establish the Warsaw International Mechanism. As noted above, the legal obligation for action on loss and damage derives directly from the objective of the Convention, found in Article 2. Actions are required to address the failure by Parties to achieve the Convention's objective, which serves as an important guide for the design and functioning of the mechanism.

Two important principles of international law - the no-harm rule and state responsibility - also establish legal obligations for historically responsible parties to take action now to address loss and damage. Under the no-harm rule of customary international law, states have a duty to "ensure that activities within their jurisdiction and control respect the environment of other states or of areas beyond national control". ${ }^{8}$ Once the no-harm rule is breached, the law of state responsibility obliges the state to "cease the act and make 'full reparation' for injury caused, including for 'any damage, whether material or moral'. Full reparation 'shall take the form of restitution, compensation and satisfaction, either singly or in combination'." Because developed countries have already emitted significant amounts of carbon dioxide and other greenhouse gases into the atmosphere, little atmospheric space, and hence space for sustainable development, is left for the rest of the world (Baer et al., 2006). Impacts on developing countries of this occupation of atmospheric space and the continuing insufficient mitigation action on the part of developed countries lead directly to loss and damage, violating the no-harm rule and obliging reparation.

The Convention establishes other relevant legal obligations, including mitigation reduction obligations under Article 4.2 and obligations addressing adaptation and the provision of the means to implement adaptation action - finance, technology transfer, and capacity building - as set out in Articles 4.1(b), 4.3, 4.4, 4.5, 4.8, and 12.1. Avoidable loss and damage results from a failure of Annex I and Annex II Parties to fulfil these specific Convention obligations.

Some countries have attempted to shift the discussion away from responsibility for atmospheric greenhouse gas concentrations by tying resulting loss and damage to the underlying vulnerabilities present in developing countries. No doubt the more vulnerable a population is, the more damage a climate event might cause. However vulnerability and other risk drivers are not the cause of losses: loss and damage result from climate impacts. Vulnerability is not the cause of drought or sea level rise; reducing vulnerability will not stop slow onset or extreme events. If an old person slowly crossing a street is hit by a car, they are hurt by the car, not their underlying vulnerability of being old and walking slowly.

\section{Evolution of the understanding for assessing and addressing loss and damage}

In 1991, in the context of the negotiations of a new international treaty on climate change, Vanuatu, on behalf of AOSIS, tabled a proposal to establish an international insurance pool to cover loss and damage from the impacts of sea level rise. 


\begin{abstract}
"The resources of the insurance pool should be used to compensate the most vulnerable small island and low-lying coastal developing countries for loss and damage resulting from sea level rise. ...

The financial burden of loss and damage suffered by the most vulnerable small island and low-lying developing countries (Group 1 countries) as a result of sea level rise shall be distributed in an equitable manner amongst the industrialized developed countries (Group 2 countries) by means of an insurance pool."
\end{abstract}

Nearly twenty years later, the UNFCCC COP finally began a significant track of work on loss and damage with its decision in 2010 (decision 1/CP.16) to establish a work program under the SBI to consider "approaches to address loss and damage associated with climate impacts in developing countries that are particularly vulnerable to the adverse effects of climate change". In 2012, work under the work program ${ }^{11}$ focused on three 'thematic areas':

- $\quad$ assessing the risk of loss and damage

- a range of approaches to address loss and damage

- the role of the Convention in enhancing implementation of approaches to address loss and damage.

The first set of activities under the work program - a technical expert meeting and technical paper on "current knowledge on relevant methodologies and data requirements as well as lessons learned and gaps identified at different levels" - addressed the first thematic area, on assessing the risk of loss and damage. The 36th meeting of the SBI adopted conclusions in June 2012 based on the outcomes of these first activities. ${ }^{12}$ The work on thematic area two - a range of approaches to address loss and damage consisted of a literature review, a technical paper on slow onset events, and four regional expert meetings. Both the SBI36 conclusions and the report from the regional meetings ${ }^{13}$ served as input to negotiations on the decision on loss and damage taken at COP18 (UNFCCC decision 3/CP.18). ${ }^{14}$

The third thematic area, on the role of the Convention, received little formal attention until COP $18 .{ }^{15}$ Parties made submissions on the third element of the work program during the last quarter of 2012, prior to the 18th meeting of the Conference of the Parties in Doha. This submission process served as the only official mechanism for Parties to present their views on what they believed was necessary and adequate form and function to address loss and damage under the auspices of the climate change convention. Table 1 summarises and provides a synthesis of what we consider were the key elements from Party submissions presented during 2012, some of which may inform current discussions on the operationalisation of the mechanism. The table contents indicate that some agreement between Parties on some of the functions required to be filled under the Convention existed, but also that there was a vast divergence of opinions between developed and developing countries over the form or mechanisms that would carry out those functions. 
Table 1 Summary and synthesis of Party submissions (2012) on the role of the Convention in addressing loss and damage

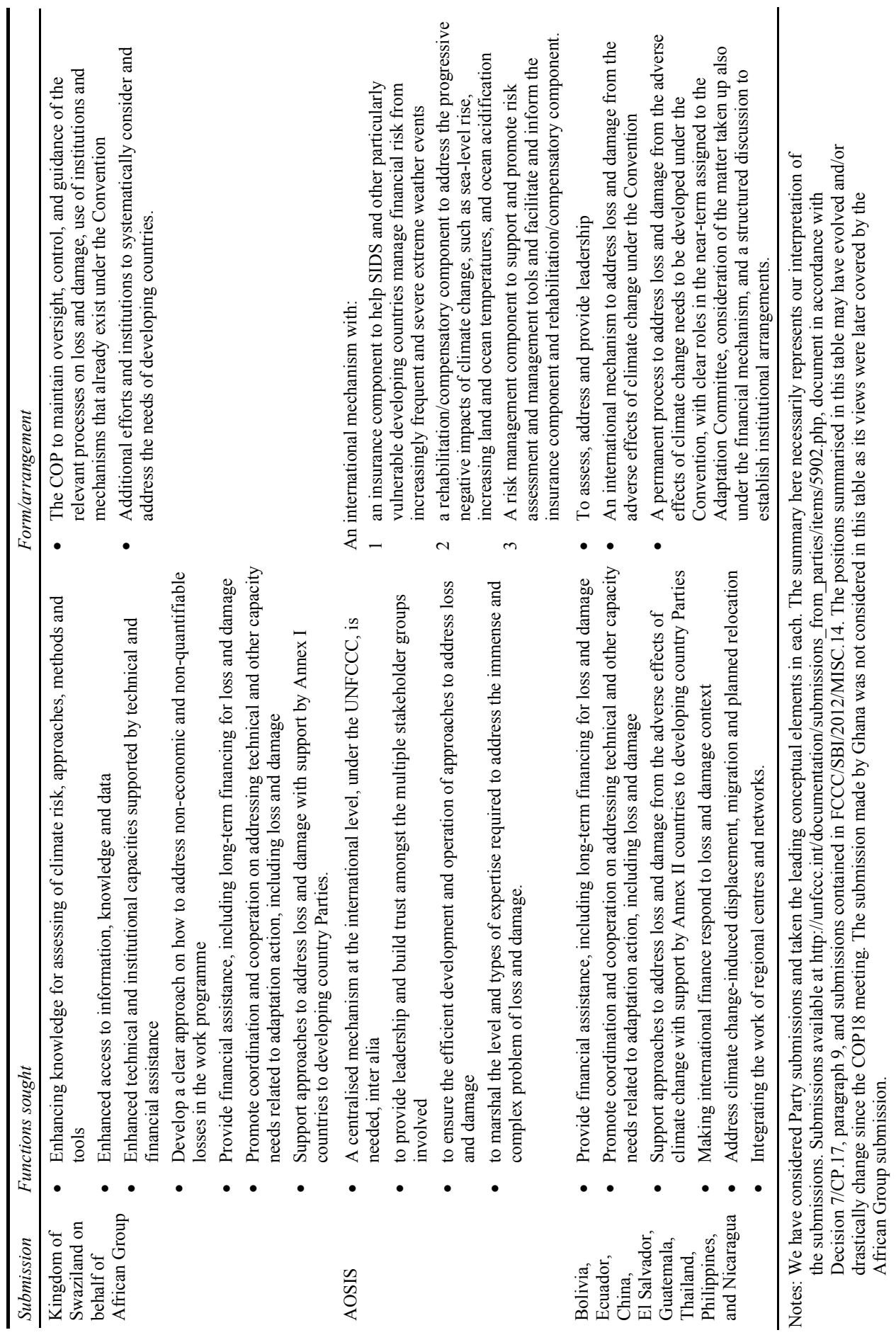


Table 1 Summary and synthesis of Party submissions (2012) on the role of the Convention in addressing loss and damage (continued)

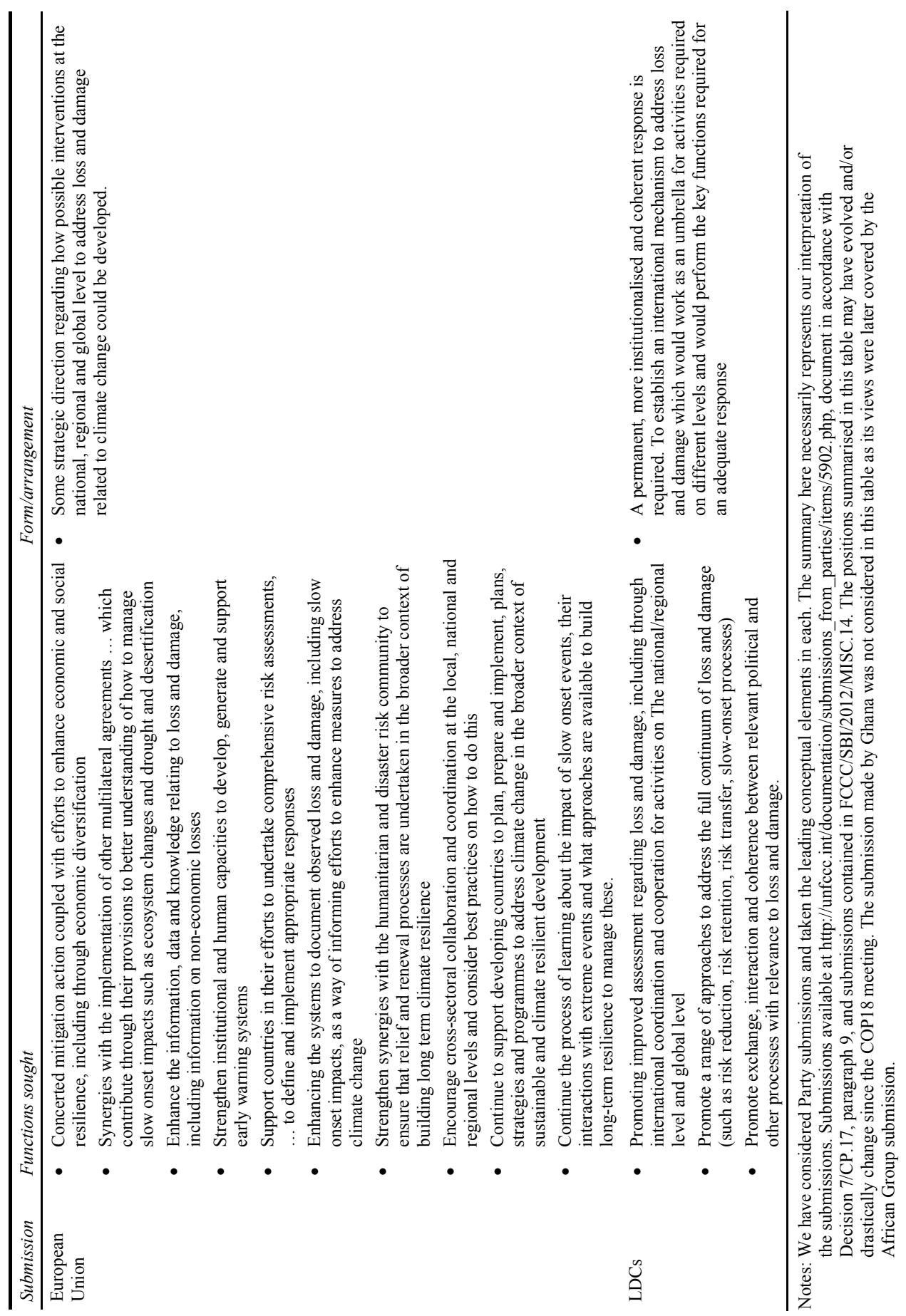


Table 1 Summary and synthesis of Party submissions (2012) on the role of the Convention in addressing loss and damage (continued)

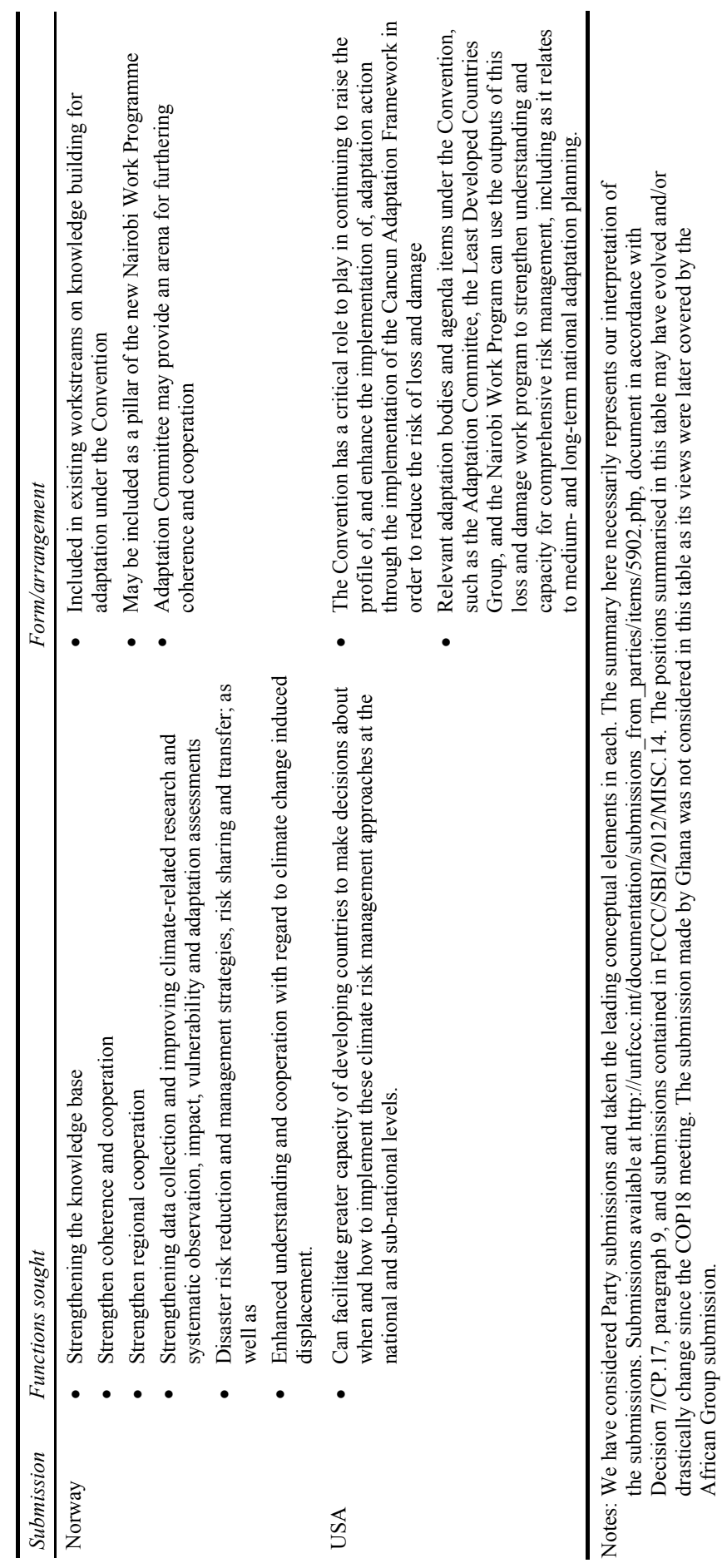


Despite little formal attention to the role of the Convention prior to Doha, debates on the first two thematic areas already pointed to several important conclusions relevant to the question of the role of the Convention, which were captured in the Doha loss and damage decision (UNFCCC decision 3/CP.18):

- there is a need to address loss and damage, even though the term is not strictly defined (as is the case of the concepts 'mitigation' and 'adaptation')

- there is a need for a systematic means to address loss and damage

- the UNFCCC has an important and fundamental role to play in addressing loss and damage.

A systematic approach to address loss and damage could, of course, have taken a range of different forms and functioned at different scales (according to Party submissions, as noted in Table 1, e.g., the AOSIS approach vs. that of Bolivia et al., or Norway). However, regardless of the scope of the approach taken, the Doha decision clearly indicated that additional steps were needed to move forward on the issue of loss and damage.

One final point must be made regarding the Doha loss and damage decision: by taking this decision, and recognising the continued relevance and need to take further measures on loss and damage associated with climate change, Parties tacitly admitted that mitigation efforts had been and would be insufficient to prevent loss and damage and that there are very real social, economic, and physical limits to adaptation.

\section{Systematically addressing loss and damage: the role of the Convention and the establishment of the WIMLD}

The important and fundamental role of the Convention in addressing loss and damage is established, inter alia, through:

- $\quad$ Article 2

- obligations established in Article 4, including paragraphs 4.4 and 4.8

- links to mitigation reduction obligations established under the Convention

- the provisions of Article 7 that allow the Conference of the Parties to establish additional arrangements to achieve its goal

- other decisions on loss and damage taken under the Convention (1/CP.16, 2/CP.17, 3/CP.18, 2/CP.19, and future decisions).

In the Doha decision on loss and damage (decision 3/CP.18), Parties highlighted and expanded on the role of the Convention (preamble and paragraph 5):

"Highlighting the important and fundamental role of the Convention in addressing loss and damage associated with climate change impacts, especially in developing countries that are particularly vulnerable to the adverse effects of climate change, including by promoting leadership, collaboration and cooperation, at the national, regional and international levels and for a broad range of sectors and ecosystems, in order to enable coherent and synergistic approaches to address such loss and damage, ... 
5. Also agrees that the role of the Convention in promoting the implementation of approaches to address loss and damage associated with the adverse effects of climate change includes, inter alia, the following:

(a) Enhancing knowledge and understanding of comprehensive risk management approaches to address loss and damage associated with the adverse effects of climate change, including slow onset impacts;

(b) Strengthening dialogue, coordination, coherence and synergies among relevant stakeholders;

(c) Enhancing action and support, including finance, technology and capacity-building, to address loss and damage associated with the adverse effects of climate change." (emphasis added)

Decision 2/CP.19 establishes the Warsaw International Mechanism for Loss and Damage, "to address loss and damage associated with impacts of climate change, including extreme events and slow onset events, in developing countries that are particularly vulnerable to the adverse effects of climate change". The decision also establishes an executive committee to guide the implementation of the functions of the mechanism. These functions build on paragraphs 5(a)-(c) of decision 3/CP.18 quoted above, and we elaborate further on those functions in the following section.

Some of the work on loss and damage under the UNFCCC could be systematically addressed by a number of existing Convention bodies. Indeed given both the scope of necessary work and the range of appropriate bodies, a division of labour among Convention bodies is more appropriate than concentrating all the work under a single committee or group. However, in establishing the Warsaw International Mechanism, Parties recognised the need to create a specific mechanism to provide leadership and enhance coordination and cooperation to enable the significant work that is required on loss and damage, avoid duplication of effort and gaps, and facilitate the work in tandem with existing bodies.

Existing institutions under the UNFCCC will take on elements of the loss and damage agenda, including the Adaptation Committee (AC), the SBI, the Green Climate Fund (GCF), the Nairobi Work Programme (NWP), the Subsidiary Body for Scientific and Technological Advice (SBSTA), the Standing Committee on Finance (SCF), the Least Developed Countries Expert Group (LEG), and the Technology Executive Committee (TEC), and the Consultative Group of Experts on National Communications from Parties not included in Annex I to the Convention (CGE). The contribution of some of these bodies was explicitly recognised and at least provisionally incorporated into the work of the mechanism through the composition of the interim executive committee, which includes two representatives each from the AC, SCF, LEG, TEC, and CGE. The Executive Committee of the mechanism can now begin the work to assign elements of the loss and damage framework to appropriate bodies, defining the type and form of institutional arrangements, whether already existing or to be created, that are capable of carrying out those functions.

An important next step to be undertaken now is the development of a two-year workplan by the interim executive committee, with a systematic and structured approach to operationalise the mechanism and begin to address the needs that had been identified by Parties during the course of the work program. 


\section{Systematically addressing loss and damage under the Warsaw International Mechanism}

In our analysis in this section, we aim to contribute our understanding of the breadth and depth of work needed under the Convention regarding loss and damage. These needs should inform the scope and content of the workplan to be developed for the WIM. We frame the analysis using the three functions of the mechanism established in UNFCCC decision 2/CP.19 paragraph 5, and base much of our contributions on the inputs made by Parties under the work program. Our objective in this final section is to identify what exact work may be needed and how that work might be carried out and enhanced under the Warsaw International Mechanism for Loss and Damage.

A Enhancing knowledge and understanding of comprehensive risk management approaches to address loss and damage associated with the adverse effects of climate change, including slow onset impacts, by facilitating and promoting:

1 action to address gaps in the understanding of and expertise in approaches to address loss and damage associated with the adverse effects of climate change, including, inter alia, the areas outlined in decision 3/CP.18, paragraph $7(a)^{16}$

2 collection, sharing, management and use of relevant data and information, including gender-disaggregated data

3 provision of overviews of best practices, challenges, experiences and lessons learned in undertaking approaches to address loss and damage. ${ }^{17}$

In this section, we discuss needs for enhancing knowledge and understanding under three specific areas where there was convergence among a number of Parties in their submissions:

1 There is a need to promote improved assessments regarding loss and damage, including through international coordination and cooperation for activities at national, regional, and global levels.

A range of activities would contribute to improving assessments that inform the identification and development of risk management approaches to address loss and damage, including but not limited to:

- enhanced understanding of the nature and risks posed by slow-onset events, including impacts on sustainable development

- coordinated and enhanced data gathering and management

- collection and development of disaggregated data for vulnerable populations, including gender-disaggregated data.

Action under the mechanism to address gaps in understanding could enhance scientific understanding of slow-onset impacts. One goal of this work may be to explore, identify, and coordinate the establishment of early warning mechanisms for different types of slow onset processes. It is also necessary to develop an understanding of impacts of both extreme and slow-onset events on sustainable development. Figure 1, from Mitchell et al. (2012), shows the short-term impacts on GDP from Hurricane Mitch in Honduras in 1998. An understanding of the risks posed by slow-onset events must include, inter alia, understanding 
the potential significant and long-term effects of such events on development prospects.

Figure 1 Observed GDP in Honduras with event vs. projected growth without event (see online version for colours)

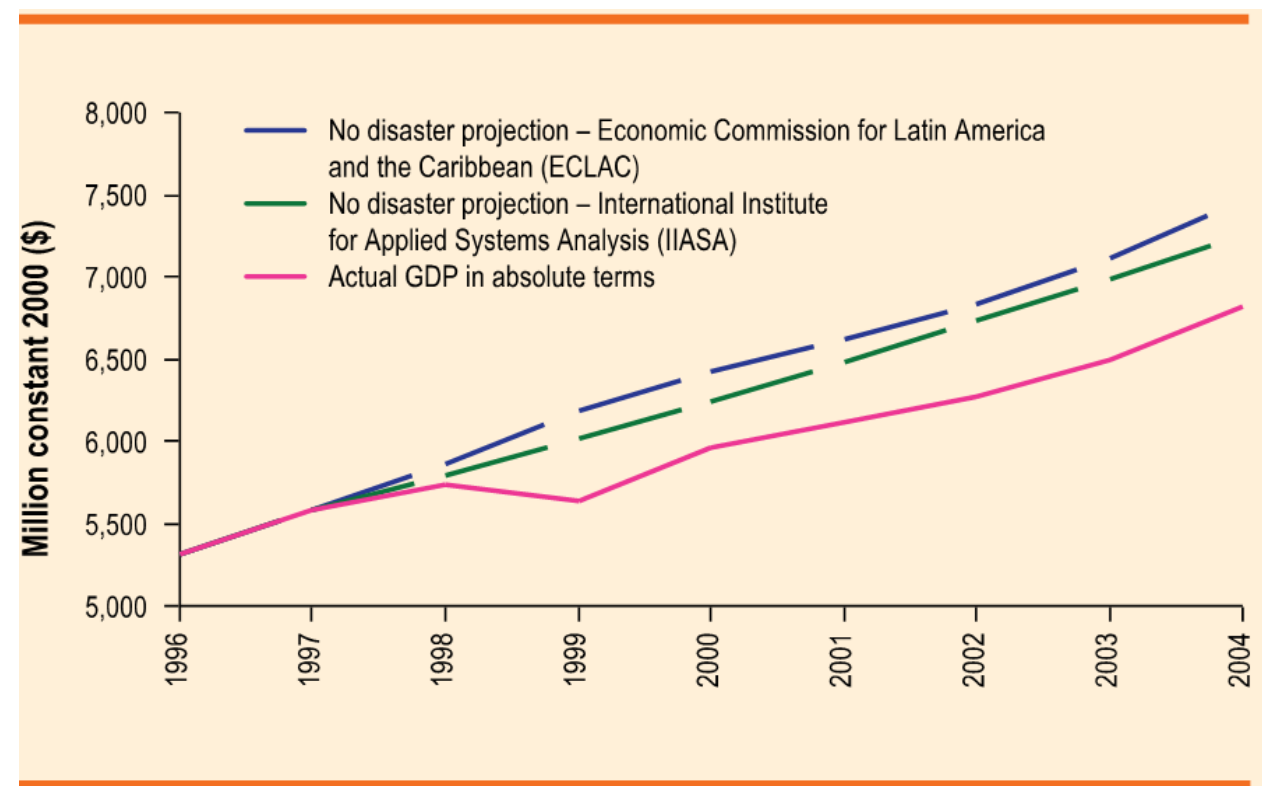

Source: Mitchell et al. (2012)

While ongoing data gathering and management related to the implementation of Article 5 of the Convention and the ongoing initiatives related to the Global Climate Observing System (GCOS) could assist in advancing matters related to assessing loss and damage, these initiatives would need to be recalibrated and enhanced to effectively and systematically respond to the specific knowledge needs related to loss and damage. Current work under Article 5 is heavily biased towards remote sensing, rather than necessary lower altitude observation research. A recalibration could serve to contribute to filling knowledge needs. Such research could contribute to assessment and understanding by, for example, looking at long-term projections and implications for socioecological systems. Other uses for data on loss and damage include establishment of baselines for insurance and risk transfer purposes, and for building knowledge necessary to determine attribution of impacts and losses to climate change.

Further, technical work to be undertaken under the mechanism could include how loss and damage affects segments of the population that are already vulnerable owing to geography, gender, age, indigenous or minority status, or disability, and how the implementation of approaches to address loss and damage can benefit those segments of the population. This technical work could not be satisfactorily accomplished outside the Convention, as no existing organisation has the mandate to deal with climate change-induced impacts on these segments of populations. Different organisations might have mandates and 
ongoing work that is relevant to these questions, but this is not systematic or focused towards understanding the relationship between climate change and those segments of population. This work could be enhanced under the mechanism by creating the necessary forums for a facilitated dialogue among key stakeholders and institutions, as well as through systematic consideration in the different knowledge generation bodies under the Convention, through the facilitation and guidance of the mechanism.

Additionally, this work needs to be enhanced by improving the practical understanding of approaches to rehabilitate from loss and damage associated with the adverse effects of climate change. Such a practical understanding would need to go hand-in-hand with implementation of actions.

2 There is a need for further understanding and development of insurance and other alternative risk-transfer approaches, such as catastrophe bonds.

Some Parties have stressed the need to understand the limits and limitations of risk-transfer approaches in addressing loss and damage, and alternatives to traditional risk-transfer approaches that could provide funds for compensation and rehabilitation in situations of catastrophes.

Some of the further work under the mechanism could include:

- development of "new and innovative insurance tools in addition to, or in conjunction with insurance pools ... [to] help manage, spread, hedge, reduce and transfer the increasing financial risk associated with climate-related hazards" (AOSIS submission)

- developing an understanding of the "ways in which insurance schemes can assist the poorest and most vulnerable people, who often have no insurable assets, including how to ensure that insurance payouts to a national government are channeled and spent in a way that benefits the poor and most vulnerable, especially in the absence of micro-insurance products that provide payouts directly to households" (SBI/2011/3)

- developing an understanding of "the necessary enabling conditions and replicability of the main common elements, institutional set-up, and the role of the partners involved in existing macro-insurance schemes such as the CCRIF, including how catastrophe bonds are used to mobilize resources to reduce risks associated with slow onset events" (SBI/2011/3).

This work cannot be completed outside the Convention because of the need for "appropriate expertise and financing to design and support this work [which must be] marshaled and coordinated at the international level". "Risk pooling requires the facilitation of access to insurance-type structure for the most vulnerable and risk transfer requires the establishment of new mechanisms whereby the extra risks to the vulnerable caused by climate change are spread more widely" (AOSIS submission). The mechanism can play a role here linked to both its first and second functions, which is described in more detail in section $\mathrm{B}$. 
3 There is a need for enhanced knowledge and understanding to strengthen comprehensive risk management approaches (assessment, reduction, transfer) related to climate change.

Better understanding under the mechanism on how to address non-economic losses could be aided by collaboration with other knowledge-generating processes focused on climate change, such as the IPCC, GCOS, and with expertise related to non-economic losses on, inter alia, biodiversity and culture, coming from other multilateral processes such as UN agencies like UNESCO and other conventions, such as the Convention on Biological Diversity (CBD). The role of enhanced social protection and other globally shared risk retention approaches are areas that can be evaluated as means of compensation, including possibly in the case of non-economic losses and adverse effects of climate change on long-term sustainable development. The threat to the survival and economic viability of many nation states stresses the urgency of the considering the issue with the involvement of many actors currently not participating in the discussions, such as financial institutions.

Some of the further work needed includes evaluation of the impacts of climate change on patterns of migration, displacement and human mobility, including linking these assessments with estimations of non-economic losses and damages associated with such migration and displacement. A key emphasis of the work will be research and action on the range of coping mechanisms that can be supported in a manner that does not undermine long-term resilience. This work could provide technical guidance related to aspects such as rehabilitation, redress, and compensation for vulnerable groups in developing countries. Such work could be systematically addressed through the international mechanism.

B Strengthening dialogue, coordination, coherence and synergies among relevant stakeholders, by

1 providing leadership and coordination and, as and where appropriate, oversight under the Convention, on the assessment and implementation of approaches to address loss and damage associated with the impacts of climate change form extreme events and slow onset events associated with the adverse effects of climate change

2 fostering dialogue, coordination, coherence and synergies among all relevant stakeholders, institutions, bodies, processes and initiatives outside the Convention, with a view to promoting cooperation and collaboration across relevant work and activities at all levels. ${ }^{18}$

Paragraph 7 in the decision, in particular subparagraphs $\mathrm{c}$ and d, gives more guidance and some elaboration of further work needed:

7(c) "Enhancing coordination, synergies and linkages among various organizations, institutions and frameworks, to enable the development and support of approaches to address loss and damage, including slow onset events and comprehensive climate risk management strategies, including risk transfer tools;"

7(d) "Strengthening and promoting regional collaboration, centres and networks on strategies and approaches, including to address loss and damage associated with the adverse effects of climate change, including slow onset 
events, including through risk reduction, risk sharing and risk transfer initiatives."

In this section, we examine in more detail further work that is needed to strengthen dialogue, coordination, coherence and synergies among institutions engaged in the loss and damage agenda, work that should be undertaken by the Warsaw International Mechanism.

1 Facilitating coordination, coherence, and enhanced dialogue with already existing institutions that cover part of the loss and damage agenda

There are a number of important global and regional institutions that are carrying out work under what might be considered a loss and damage agenda, particularly in the areas of risk management, risk reduction, and risk transfer. The UN Office for Disaster Risk Reduction (UNISDR) and the Hyogo Framework for Action; the World Meteorological Organisation (GCOS and GFCS) as described above; the UN High Commissioner for Refugees (UNHCR) and the International Organization for Migration (IOM); the UN Convention to Combat Desertification; the United Nations Development Programme; and several regional risk transfer mechanisms, such as the Caribbean Catastrophe Risk Insurance Facility (CCRIF) all currently or in the future have some role to play in assessing and addressing loss and damage. However, as recognised in the Doha and Warsaw decisions, there is a need to strengthen dialogue, coordination, and coherence, and enhance potential synergies among these institutions, and this dialogue needs to be guided.

Some of the further work undertaken under the mechanism could include regular joint meetings on specific issues of overlap between sets of organisations and joint work negotiated through a Memorandum of Understanding. The Adaptation Committee could assist and "play a catalytic role in this regard and ... provide an arena for furthering coherence and cooperation in this regard", (Norway submission) following on its mandate to engage with, draw on the expertise of, and seek input from institutions outside the Convention (established under decision 2/CP.17).

An example of a set of institutions that could collaborate on joint work, coordinated under the mechanism, would be the UNHCR, IOM, the Nansen Initiative, and the UNFCCC Adaptation Committee. Joint work could include developing synergistic and coherent approaches to assess climate change induced displacement, and developing and supporting approaches to address human migration, displacement, and mobility related to climate change. This work is already mandated under the Adaptation Framework in decision 1/CP.16, paragraph 14(f). The decision invited all Parties to undertake "measures to enhance understanding, coordination and cooperation with regard to climate change induced displacement, migration and planned relocation, where appropriate, at national, regional and international levels".

This particular work on displacement, migration and planned relocation cannot be done outside the Convention because no institution has the broad, overarching mandate on loss and damage possessed by the Convention to enable making broad linkages between loss and damage and human mobility issues. No global agreement provides criteria or quotas for the admission of the citizens of 
one State into the territory of another. Nor is there academic or policy consensus on the construction of a definition of environmental or climate change-displaced persons (Warner and Hoffmaister, 2013).

Other arenas of overlapping expertise, such as international scientific efforts to understand progression and impacts of slow onset events, and data gathering and management of indicators and baselines for both risk transfer and attribution purposes, will also require leadership under the mechanism linked to its overarching mandate to convene other international bodies on issues of loss and damage. Some of this work could further include a more formal collaboration with relevant agencies and build on experiences with the GCOS Cooperation Mechanism (GCM). Covering the broad set of issues linked to assessing and addressing loss and damage could serve as a model to begin advancing the work.

2 Promoting coordination and coherence with ongoing efforts on disaster risk reduction.

UNISDR coordinates international efforts in disaster risk reduction (DRR) and guides the implementation of the Hyogo Framework for Action on disaster risk reduction. Given the intersections of the UNISDR agenda on DRR with the loss and damage agenda, continued cooperation and coordination between UNFCCC and UNISDR is clearly essential.

Some of the work under the mechanism could further include regular invitations to the UNISDR Secretariat to report on progress towards a post-2015 framework for disaster risk reduction, with an emphasis on linkages with the UNFCCC, climate change adaptation, risk management, and loss and damage agendas. The UNISDR could also be invited to report on its ongoing support to countries to integrate disaster risk reduction into National Adaptation Plans (UNISDR, 2012). These efforts could be means to catalyse "partnerships for implementation ... to break down silos between the adaptation and DRR communities" (SBI/2011/INF.11). The Adaptation Committee could also play a role in facilitating this continued interchange of information.

3 Promoting coordination and coherence of ongoing regional and international efforts to develop effective and accessible collective risk transfer mechanisms.

Parties agree on the need for collective risk transfer mechanisms. In the series of regional expert meetings on loss and damage, there was significant emphasis placed on successful risk transfer mechanisms such as the CCRIF. However it has been continually noted, particularly by AOSIS, that much work is still needed to develop regional and international means for insuring against extreme events, including through risk transfer, risk sharing, and risk pooling.

Some of the further work on this element of the loss and damage agenda could include coordination under the mechanism of regional and international efforts to:

- $\quad$ assist SIDS, LDCs, and other particularly vulnerable developing countries in better managing financial risks (AOSIS submission)

- develop new and innovative insurance tools in addition to or in conjunction with insurance pools (AOSIS submission) 
- "regularly bring together information on new modalities and mechanisms on insurance and reinsurance, and related technical expertise and advice in order to inform the process" (SBI/2011/INF.11).

The Convention is the only international institution with the capability to marshal and coordinate at the international level the appropriate expertise and financing to design and support this work. The specific arrangements of such mechanisms may vary, but the leadership of the Convention can enable the coherence and oversee the effectiveness of such mechanisms.

C Enhancing action and support, including finance, technology and capacity-building, to address loss and damage associated with the adverse effects of climate change, so as to enable countries to undertake actions pursuant to decision 3/CP.18, paragraph 6, by:

1 provision of technical support and guidance on approaches to address loss and damage associated with climate change impacts, including extreme events and slow onset events

2 provision of information and recommendations for consideration by the Conference of the Parties when providing guidance relevant to reducing the risks of loss and damage, where necessary, addressing loss and damage, including to the operating entities of the financial mechanism of the Convention, as appropriate

3 facilitating the mobilisation and securing of expertise, and enhancement of support, including finance, technology and capacity-building, to strengthen existing approaches and, where necessary, facilitate the development and implementation of additional approaches to address loss and damage associated with climate change impacts, including extreme weather events and slow onset events. ${ }^{19}$

In the context of the Doha decision on loss and damage, developed country Parties are requested to provide support to developing countries with finance, transfer of technology, and capacity-building. Continued work under the Convention and the Warsaw International Mechanism will provide insight into the specific nature of the types and amount of support needed and provided. Below we provide more detail for further work on four specific finance, technology, and capacity-building elements of the loss and damage agenda.

1 Making international finance respond to the loss and damage context.

Financial shocks and lost development opportunities from large-scale economic disruption brought on by slow-onset and/or extreme climate change hazards will require significant coordination of international trade and investment flows. The Convention, as the policy-relevant forum, has the capacity to convene discussions under the mechanism on how financial measures could assist countries in coping with loss and damage, for example deferral of payments to international institutions, debt relief, and other similar measures.

Some of the further work could include:

- convening bilateral and multilateral funding agencies, and other relevant stakeholders to develop a suite of options for financial measures to assist countries in coping with loss and damage from slow onset events 
- enhancing the understanding, coordination, and cooperation of financial measures which could assist developing countries in rapidly recovering after occurred disasters.

The Convention and the Warsaw International Mechanism have a key role in addressing this need because of knowledge of loss and damage, as well as expertise in providing climate finance. Loss and damage is long-term, yet existing institutions are best equipped to deal with short-term crises. The developing knowledge and expertise under the Convention around what slow-onset disasters are likely to look like, how slow-onset processes can exacerbate the damage from extreme events, and understanding of limits to adaptation to slow-onset events is necessary to inform these discussions. Similarly, the developing expertise under the Convention on the limits to traditional risk transfer approaches must also inform development of financial measures aimed at assisting vulnerable countries in recovery and rehabilitation after extreme events.

2 Ensuring development of adequate risk transfer options for burden sharing after catastrophic impacts.

Collective risk sharing will be an essential component of a coordinated global response to loss and damage. As noted in previous sections, work under the Convention and the Warsaw International Mechanism should provide direction and coordination to ensure that financial contributions of global and regional risk sharing mechanisms can substantially contribute to addressing loss and damage from extreme events and other catastrophic climate change impacts.

Some of the work could further include examining the role and potential modalities (including its finance) of a climate risk insurance facility to assist particularly vulnerable developing countries in risk sharing and transfer. It could also include establishing and supporting regional networks that can promote and facilitate cooperation on policy coherence and regulations related to loss and damage, baseline activities essential for a functioning insurance and compensation mechanism.

No multilateral institution, including the UNFCCC, has the adequate channels of cooperation with the relevant stakeholders involved in the development of necessary financial instruments. However, consistent with the Doha and Warsaw decisions and article 4.8 of the Convention, the development of such instruments is considered by developing countries as a necessity (as seen in their submissions) and the UNFCCC could launch such initiatives, including through the GCF.

3 Enhancing action and support for climate-resilient development.

Countries need support for development pathways that enhance climate resilience while seeking to eradicate poverty that is an underlying driver of vulnerability to climate impacts.

Some of the work needed in this area includes:

- fostering proactive adaptation planning which can reduce loss and damage, with an enhanced understanding of loss and damage in the context of development pathways 
- $\quad$ strengthening synergies with the humanitarian and disaster risk community to ensure that relief and renewal processes are undertaken in the broader context of building long-term climate resilience (EU submission).

There is a plethora of institutions involved in development planning, including multilateral agencies, such as the World Bank and UNDESA, national institutions, and planning and finance ministries. However, while the Convention is not the forum to discuss development, it is an appropriate forum to enhance action for climate-resilient development. Under the Convention, the international mechanism can exercise leadership and its convening power to bring the necessary stakeholders to discuss and develop a common approach on what loss and damage means for climate-resilient, sustainable development, and what Parties will require in terms of finance, technology, and capacity in order to achieve such development.

4 Ensuring development of financial measures adequate to deal with slow-onset impacts and impacts on sustainable development.

Addressing loss and damage resulting from slow-onset processes, in the context of sustainable development, will require different approaches than those used to address financial shocks resulting from extreme events. For example, slow-onset impacts may permanently diminish the tourism industry in many developing countries due to the loss of ecosystems, animal and plant diversity, and other tourist-attracting resources.

Some of the work ahead could further include identifying a range of possible financial options for addressing slow-onset disasters. One option worth developing is the setting up and strengthening of social protection systems, including systems that can be scaled up in advance of growing impacts (EC, 2012).

As with the development of other financial measures, this cannot be done well outside the Convention because no multilateral institution, including the UNFCCC, has the knowledge on loss and damage and adequate channels of cooperation with the relevant stakeholders involved in the development of necessary financial instruments necessary. This knowledge and channels will emerge from the overall work of the Convention and the international mechanism for loss and damage. The work needs to be enhanced by linking the development of financial measures with the efforts to collect relevant data, establish baselines, and gather other essential information necessary to design appropriate financial arrangements.

\section{Conclusions}

In this paper, we have briefly reviewed the history of and rationale for the mechanism, reviewed the legal rationale for addressing loss and damage under the UNFCCC, and analysed the role of the Convention in systematically addressing loss and damage associated with the impacts of climate change in developing countries that are particularly vulnerable to the adverse effects of climate change. In doing so, it was our 
intent to provide an informed perspective on loss and damage under the UNFCCC from inside the negotiations.

Our concluding section outlined multiple areas where further consideration is needed to continue the work initiated under the work program, and which should be integrated into the two-year workplan of the mechanism and its executive committee, also identifying where efforts could be enhanced and other bodies under which this work could happen. We are providing a starting set of elements for the work of the mechanism, based on the work since 2010. Of course, as climate science evolves, the Mechanism will need to develop new modalities to respond to the evolving challenge.

Small, important steps have been taken on the road to understanding and addressing loss and damage, in particular with the establishment of the Warsaw International Mechanism for Loss and Damage, but the work ahead is vast. Climate impacts are growing in frequency and magnitude and slow-onset processes continue unabated. There is a compelling need for the UNFCCC to now prioritise the work of the mechanism to assess and address loss and damage from the adverse effects of climate change.

While much of the work needed on loss and damage will take place outside the umbrella of the Convention and the Warsaw International Mechanism, it cannot be expected to emerge spontaneously without an institution playing a leadership, coordination, and catalytic role - a role that is logically played by the Convention and the new mechanism. Indeed, the Convention has become the de facto policy-relevant forum at the global level for discussion and work related to this challenge. This does not mean that it and the Warsaw International Mechanism will need to undertake all the work required on loss and damage at the global level, but in key instances they will play a leadership role to foster initiatives to be undertaken by other actors. Understanding and work related to loss and damage will evolve over time; the Warsaw International Mechanism is key to ensure such evolution is carried forward in a coherent manner and addressing emerging needs.

\section{References}

ActionAid, CARE International, Germanwatch, and World Wildlife Fund (2012a) Into Unknown Territory: The Limits to Adaptation and Reality of Loss and Damage from Climate Impacts, ActionAid, CARE International, Germanwatch, World Wildlife Fund [online] http://www.careclimatechange.org/files/CARE_docs/2012_Into\%20Unknown\%20Territory_J oint\%20Report.pdf (accessed 11 November 2014).

ActionAid, CARE International, and World Wildlife Fund (2012b) Tackling the Limits to Adaptation: An International Framework to Address 'Loss and Damage' from Climate Change Impacts, ActionAid, CARE International, World Wildlife Fund [online] http://www.careclimatechange.org/files/Doha_COP_18/tackling_the_limits_lr.pdf (accessed 11 November 2014).

Anderson, K. and Bows, A. (2011) 'Beyond 'dangerous' climate change: emission scenarios for a new world', Philosophical Transactions of the Royal Society, Vol. 369, No. 1934, pp.20-44.

Baer, P., Athanasiou, T., Kartha, S. and Kemp-Benedict, E. (2006) The Greenhouse Development Rights Framework, Heinrich Böll Foundation, Christian Aid, EcoEquity, Stockholm Environment Institute, Berlin.

Dow, K., Berkhout, F., Preston, B.L., Klein, R.J.T., Midgley, G. and Shaw, M.R. (2013) 'Limits to adaptation', Nature Climate Change, Vol. 3, pp.305-307. 
European Commission (EC) (2012) Social Protection in European Union Development cooperation, Communication from the Commission to the European Parliament, the Council, the European Economic and Social Committee and the Committee of the Regions, $\operatorname{COM}(2012) 446$ final, 20 August.

Hossain, M. (2010) 'Global warming induced sea level rise on soil, land and crop production', 19th World Congress of Soil Science, Soil Solutions for a Changing World, 1-6 August 2010, Soil Resource Development Institute, Bangladesh Ministry of Agriculture, Brisbane, Australia [online] http://www.iuss.org/19th\%20WCSS/Symposium/pdf/0419.pdf (accessed 11 November 2014).

Intergovernmental Panel on Climate Change (IPCC) (2014) Climate Change 2014: Impacts, Vulnerability, Adaptation, Working Group II Contribution to the Fifth Assessment Report of the Intergovernmental Panel on Climate Change (to be published Fall 2014).

Kates, R.W., Travis, W.R. and Wilbanks, T.J. (2012) 'Transformational adaptation when incremental adaptations to climate change are insufficient', Proceedings of the National Academy of Sciences, Vol. 109, No. 19, pp.1756-1761, doi/10.1073/pnas.1115521109.

Mitchell, T., Mechler, R. and Harris, K. (2012) Tackling Exposure: Placing Disaster Risk Management at the Heart of National Economic and Fiscal Policy, May, CDKN Guide [online] http://www.preventionweb.net/files/globalplatform/entry bg paper cdkntacklingexposuremitchell1[1].pdf (accessed 11 November 2014).

New, M., Liverman, D., Schroder, H. and Anderson, K. (2011) 'Four degrees and beyond: the potential for a global temperature increase of four degrees and its implications', Philosophical Transactions of the Royal Society, Vol. 369, No. 1934, pp.6-19.

Rogers, C. (2012) 'Economics of climate change adaptation: case for action', Presentation to Asian and Eastern European Regional Expert Meeting on a Range of Approaches to Address Loss and Damage Associated with the Adverse Effects of Climate Change, Including Impacts Related to Extreme Weather Events and Slow Onset Events, 27-29 August, Bangkok, Thailand [online] http://unfecc.int/files/adaptation/cancun_adaptation_framework/loss_and_damage/ application/pdf/unfccc_charles_adb.pdf (accessed 11 November 2014).

UNFCCC (2012) Background paper to the Regional Expert Meetings on: A range of approaches to Address Loss and Damage Associated with the Adverse Effects of Climate Change, Including Impacts Related to Extreme Weather Events and Slow-Onset Processes, Unpublished, on file with authors.

UNISDR (2012) Background Note: Coherent Action by the UN System to Reduce Disaster Risk and Build Resilience, October [online] http://www.preventionweb.net/files/30004 informationnoteonunsystemwidecoordi.pdf (accessed 11 November 2014).

Verheyen, R. and Roderick, P. (2008) Beyond Adaptation, WWF-UK.

Warner, K. and Hoffmaister, J. (2013) 'Migration, vulnerability, and community based adaptation', submitted to Climate and Development.

\section{Notes}

1 UNFCCC Decision 1/CP.16, paragraph 3.

2 See for example a recent editorial in the popular science magazine New Scientist:

'Wild weather: extreme is the new normal', New Scientist, 18 January [online] http://www.newscientist.com/article/mg21729003.200-wild-weather-extreme-is-the-newnormal.html (accessed 11 November 2014); and http://www.usatoday.com/story/weather/2013/03/20/weather-extremes-global-warmingclimate-change-louis-uccellini/2003513 (accessed 11 November 2014), where the head of the U.S. National Weather Service, Louis Uccellini, calls recent weather extremes a 'new normal'.

3 UNFCCC Decision 3/CP.18, paragraph 9.

4 Decision 2/CP.19, Warsaw International Mechanism for Loss and Damage associated with climate change impacts. UNFCCC COP 19, Warsaw 2013. 
5 Loss and damage is defined in the background paper as "the actual and/or potential manifestation of impacts associated with climate change in developing countries that negatively affect human and natural systems."

6 As defined in the background glossary distributed by the UNFCCC Secretariat (unpublished, on file with authors) at the regional expert meeting on: A range of approaches to address loss and damage associated with the adverse effects of climate change, including impacts related to extreme weather events and slow onset processes.

7 As defined in the background glossary distributed by the UNFCCC Secretariat (unpublished, on file with authors) at the regional expert meeting on: A range of approaches to address loss and damage associated with the adverse effects of climate change, including impacts related to extreme weather events and slow onset processes.

81996 ICJ Advisory Opinion in the Legality of the Threat or Use of Nuclear Weapons, as cited in Verheyen and Roderick (2008).

9 Verheyen and Roderick (2008) citing the International Law Commission.

10 Document A/AC.237/WG.II/CRP.8.

11 As set out in UNFCCC Decision 7/CP.17.

12 UNFCCC Report of the 36th meeting of the Subsidiary Body on Implementation, 23 May 2012, FCCC/SBI/2012/L.12.

13 UNFCCC Report on the regional expert meetings on a range of approaches to address loss and damage associated with the adverse effects of climate change, including impacts related to extreme weather events and slow onset events, note by the secretariat, 19 November 2012, $\mathrm{FCCC} / \mathrm{SBI} / 2012 / 29$.

14 The work of the work program in 2012 is usefully summarised by the UNFCCC Secretariat on the UNFCCC website: http://unfccc.int/adaptation/cancun_adaptation_framework/loss and_damage/items/6056.php (accessed 11 November 2014).

15 Two informal sessions brought negotiators together in October 2012 (Berlin) and December 2012 (Doha, immediately prior to the COP). The role of the Convention was a central topic for these sessions.

16 UNFCCC Decision 3/CP.18, paragraph 7:

7. Acknowledges the further work to advance the understanding of and expertise on loss and damage, which includes, inter alia, the following:

(a) Enhancing the understanding of:

(i) The risk of slow onset events, and approaches to address them;

(ii) Non-economic losses and damages;

(iii) How loss and damage associated with the adverse effects of climate change affects those segments of the population that are already vulnerable owing to geography, gender, age, indigenous or minority status, or disability, and how the implementation of approaches to address loss and damage can benefit those segments of the population;

(iv) How to identify and develop appropriate approaches to address loss and damage associated with the adverse effects of climate change, including to address slow onset events and extreme weather events, including through risk reduction, risk sharing and risk transfer tools, and approaches to rehabilitate from loss and damage associated with the adverse effects of climate change; 
(v) How approaches to address loss and damage associated with the impacts of climate change may be integrated into climateresilient development processes;

(vi) How impacts of climate change are affecting patterns of migration, displacement and human mobility;

(b) Strengthening and supporting the collection and management of relevant data, including gender-disaggregated data, for assessing the risk of loss and damage associated with the adverse effects of climate change;

(c) Enhancing coordination, synergies and linkages among various organizations, institutions and frameworks, to enable the development and support of approaches to address loss and damage, including slow onset events and comprehensive climate risk management strategies, including risk transfer tools;

(d) Strengthening and promoting regional collaboration, centres and networks on strategies and approaches, including to address loss and damage associated with the adverse effects of climate change, including slow onset events, including through risk reduction, risk sharing and risk transfer initiatives;

(e) Enhanced capacity-building at the national and regional levels to address loss and damage associated with the adverse effects of climate change;

(f) Strengthening institutional arrangements at the national, regional and international levels to address loss and damage associated with the adverse effects of climate change.

17 UNFCCC Decision 2/CP.19, paragraph 5(a).

18 UNFCCC Decision 2/CP.19, paragraph 5(b)

19 UNFCCC Decision 2/CP.19, paragraph 5(c). 